JURNAL ILMIAH ELEKTRONIKA DAN KOMPUTER, Vol.14, No.1, Juli 2021, pp. 152 - 161

p-ISSN : 1907-0012 (print)

e-ISSN : 2714-5417 (online)

http://journal.stekom.ac.id/index.php/elkom

\title{
Analisa Interaksi Pegawai Pada CV. Diamond Printing Menggunakan Social Network Analysis (SNA)
}

\author{
Budi Santoso', Danny Manongga², Irwan Sembiring ${ }^{3}$ \\ ${ }^{123}$ Fakultas Teknologi Informasi, Program Studi Magister Sistem Informasi \\ Jl. Diponegoro No.52-60, Salatiga, Kec. Sidorejo, Kota Salatiga, Jawa Tengah 50711, (0298) 321212
}

\begin{tabular}{|c|c|}
\hline ARTICLE INFO & ABSTRACT \\
\hline $\begin{array}{l}\text { Article history: } \\
\text { Received } 23 \text { maret } 2021 \\
\text { Received in revised form } 29 \text { Juni } 2021 \\
\text { Accepted } 29 \text { Juli } 2021 \\
\text { Available online July } 2021\end{array}$ & $\begin{array}{l}\text { CV. Diamond Printing is one of the largest offset } \\
\text { printing companies with } 32 \text { years of experience and } \\
\text { is located in the city of Surabaya, East Java. Data } \\
\text { from HRD managers explained that there was no } \\
\text { report from observations related to employee work } \\
\text { effectiveness in terms of coordination and synergy } \\
\text { between employees as seen from the communication } \\
\text { and collaboration relationships. The absence of data } \\
\text { related to the effectiveness of the performance of CV } \\
\text { employees. Diamond Printing in terms of } \\
\text { communication network mapping is one of the } \\
\text { obstacles faced by HRD in determining KPI (key } \\
\text { performance indicator). By using the Social Network } \\
\text { Analysis (SNA) method with the help of UCINET } 6 \\
\text { software, it is hoped that some employees will have } \\
\text { advantages, especially in collaboration and } \\
\text { communication in group network structures. There } \\
\text { are three parameters used in SNA, including: degree } \\
\text { centrality, closeness centrality, and betweenness } \\
\text { centrality. This study involved 104 respondents (the } \\
\text { entire population) with a sampling technique using } \\
\text { snowball sampling and a questionnaire as a means } \\
\text { of collecting data. The results of this study indicate } \\
\text { that most of the collaboration and communication } \\
\text { network interactions are dominated by manager } \\
\text { level employees and department heads. Based on } \\
\text { these findings, an innovation is needed from all } \\
\text { stakeholders from CV. Diamond Printing in } \\
\text { developing effective communication methods } \\
\text { between its members. }\end{array}$ \\
\hline
\end{tabular}

Keywords: Communication Network, Social

Network Analysis, Key Performance Indicator

\section{PENDAHULUAN}

Perusahaan atau organisasi dalam era globalisasi dalam menyongsong era industri 4.0 sangat dibutuhkan kemampuan untuk melakukan adaptasi baik dari segi teknologi tetapi juga segi komunikasi antar individu dalam perusahaan untuk mencapai efisiensi dan efektivitas sehingga tercapai tujuan bersama. Komunikasi merupakan hal yang sangat penting di kehidupan sosial masyarakat, hal ini juga sama diperlukan juga oleh suatu organisasi yang terdiri dari sekumpulan 
orang yang memiliki tujuan yang sama [1]. Dalam sebuah organisasi atau perusahaan seringkali terdapat kebuntuan falam komunikasi antar pegawai, baik komunikasi formal terkait pekerjaan maupun komunikasi informal terkait hal-hal diluar profesionalitas. Biasanya komunikasi informal masih terkendala dan terkadang hal itu terjadi diluar pekerjaan karyawan atau karir profesionalitasnya, sehingga pola komunikasi tersebut perlu dianlisis [2]. Apabila tidak ditangani dengan baik akan dikhawatirkan akan terbawa dalam pekerjaan serta mempengaruhi kinerja dari pegawai tersebut dan berdampak dapa efektifitas organisasi atau perusahaan.

CV. Diamond Printing merupakan salah satu perusahaan percetakan offset terbesar yang terletak di kota Surabaya, Jawa Timur. Perusahaan ini pertama kali berdiri tanggal 8 Agustus tahun 1988 dan didirikan oleh bapak Danny Goentoro dan rekan. Dahulu pada awal didirikan, perusahaan masih menggunakan mesin cetak satu warna dan belum didukung secara optimal oleh karyawan bagian finishing dan pracetak, dimana sebagian besar perusahaan percetakan masih menggunakan jasa pihak ketiga untuk proses tersebut pada saat itu.

Berkembangnya waktu dan teknologi di bidang offset, CV. Diamond Printing meningkatkan kapasitas produksi kepada konsumen agar timbul kepercayaan serta efisiensi produk dan layanan. Dalam bagian atau departemen finishing saat ini dilengkapi dengan berbagai mesin penunjang, seperti mesin laminating, qluing dan punching. CV. Diamond Printing saat ini juga dilengkapi dengan mesin computer to plate (CTP) yang didukung dengan kalibrasi digital dan karya seni grafis komputer.

CV. Diamond Printing saat ini kurang lebih memiliki sekitar 104 orang karyawan yang bekerja pada berbagai departemen atau bagian, diantaranya printing, finishing, production, operational, cutting, dan driver. Manajemen perusahaan dituntut untuk dapat merumuskan konsep kebijakan dalam mengelola sumber daya manusia perusahaan dapat berkembang sesuai dengan kebutuhan perusahaan [3], diantaranya dalam mengukur efektifitas dan efisiensi kinerja berdasarkan pola hubungan komunikasi. Komunikasi menjadi berperan sentral sehingga dapat mempengaruhi kinerja pegawai atau karyawan [4]. Metode Social Network Analysis (SNA) dapat memperlihatkan hubungan komunikasi serta pola yang bisa diidentifikasi melalui peran setiap aktor atau individu karyawan dan melalui gambaran sociogram.

Penelitian terdahulu adalah pengamatan awal terhadap fakta awal yang berasal dari sebuah kegiatan penelitian yang kelak bisa menjadi sebuah dasar komparasi atau perbandingan dengan penelitian yang saat ini dilakukan. Sebuah penelitian yang ingin mengetahui pola hubungan para aktor atau individu yang bekerja di UKM Batik Windasari kabupaten Sragen, Jawa Tengah. Pola hubungan ini sangat berguna untuk mendeteksi pola komunikasi para aktor untuk memenangkan persaingan produk ekonomi kreatif terutama dari negara Batik China dan kawasan ASEAN. Penelitian ini menganalisis 60 aktor dari seluruh karyawan UKM Windasari kabupaten Sragen. Metode pengambilan sampel dalam penelitian ini menggunakan sampel jenuh atau seluruh anggota populasi dijadikan sebagai responden. Hasil penelitian menunjukkan hubungan antar pelaku UMKM batik Windasari sangatlah lemah dimana masih bergantung pada aktor atau individu tertentu sebagai perantara, sehingga kolaborasi kurang efektif [5].

Dalam penelitian yang menganalisis terkait pemetaan jaringan komunikasi pada karyawan Multifinance dengan menggunakan social network analysis (SNA). Penelitian ini dilakukan pada responden seluruh SDM perusahaan multifinance PT. BFI cabang Salatiga sebanyak 36 responden/aktor. Metode yang digunakan dalam pengambilan data adalah snowball sampling dengan menggunakan program UCINET 6 sebagai software pengolahnya. Hasil penelitian menunjukkan bahwa sentralitas kedekatan dan hubungan terdapat pada aktor/responden yang bekerja pada divisi operasi, divisi pengumpulan dan divisi kredit [2].

Terdapat sebuah mencoba riset yang mencoba meneliti terkait pola interaksi sosial pada komunitas Himpunan Mahasiswa dan Pelajar Papua Barat/HIMPPAR di kota Salatiga. Penelitian ini menggunakan media sosial Facebook sebagai data yag diolah untuk mengetahui relasi sosial yang terjadi dengan metode social network analysis (SNA). Hasi menunjukkan terdapat 10 elemen dalam komunitas HIMPPAR yang memiliki peran penting dalam penyampaian informasi melalui jejaring sosial organisasi yang diukur menggunakan centrality dan closeness [6]. 
Berdasarkan beberapa penelitian terdahulu terkait SNA, diharapkan CV. Diamond Printing dapat mengembangkan potensi komunikasi yang efektif dengan mempelajari hasil penelitian terkait pola hubungan karyawan dengan menggunakan SNA. Dalam hal ini ada beberapa parameter yang dianalisis dalam metode social network analysis (SNA), yaitu :

\section{a. Level Sistem}

Level sistem merupakan interpretasi secara komperhensif tentang sebuah jaringan yang lebih menggambarkan struktur jaringan dan karakteristik jaringan, dimana dalam melakukan pengukuran sebuah struktur jaringan serta karakteristik jaringan sebuah komponen kepadatan jaringan (density) dapat dipergunakan dengan melakukan komprasi atau perbandingan [7].

\section{b. Pengukuran Sentralitas}

Pengujian hubungan atau relasional dalam sebuah organisasi atau kelompok menggunakan Social Network Analysis (SNA) dilakukan melalui tiga tahapan, diantaranya Degree Centrality (derajat sentralitas), Closenness Centrality (sentralitas kedekatan), dan Betweenness Centrality (sentralitas antara) [8]. Didalam Degree Centrality akan diketahui para aktor yang memiliki jaringan koneksi luas dan dianggap populer yang ditunjukkan dengan tingginya nilai indegree (dihubungi aktor lain) dan outdegree (menghubungi aktor lain) [9]. Closenness Centrality lebih memperlihatkan para aktor yang memiliki jalur terpendek atau tercepat dalam menjangkau hubungan serta mnyebarkan informasi kepada aktor lainnya [9]. Sedangkan Betweenness Centrality menunjukkan para aktor yang mempunyai kemampuan untuk mengendalikan sebuah informasi serta memiliki komunikasi paling baik dalam sebuah hubungan kelompok (relasional) [10].

c. Klik

Klik merupakan pengelompokkan dari kumpulan aktor atau individu dalam suatu jaringan dengan menambahkan semua hubungan antar aktor yang melakukan interaksi dengan semua anggota kelompok atau organisasi [11], [12]. Teknik yang digunakan untuk mengetahui jumlah klik atau hubungan yang terjadi antara beberapa aktor dengan menggunakan UCINET 6 software. Tidak terdapat suatu acuan baku terkati limit maksimal minimal anggota dalam klik, akan tetapi minimal terdapat 3 hubungan yang terjalin antar aktor dengan beberapa aktor lainnya dalam sati kelompok [9].

\section{d. Graf}

Graf merupakan struktur sebuah jaringan yang bermanfaat untuk membuat modelling dalam relational relationship dengan objek seorang aktor dengan menggunakan metode Social Network Analysis (SNA), dimana bentuknya membentuk simbol berupa kumpulan hubungan titik (node) yang berkaitan dan membentuk sebuah sosiogram [13]. Dalam sosiogram terdapat hubungan yang terarah dengan edge atau simbol garis, yang berfungsi membantu memetakan sebuah hubungan setiap aktor dalam organisasi [13].

\section{METODE PENELITIAN}

Dalam penelitian ini peneliti memilih objek penelitian terkait mengamati serta menganalisis hubungan komunikasi antar karyawan di CV. Diamond Printing dengan model kuantitatif deskriptif. Penelitian ini menggunakan kuesioner sebagai perangkat dalam pengumpulan data dengan menggunakan teknik sampling sampel jenuh, yaitu seluruh anggota populasi dalam hal ini karyawan CV. Diamond Printing dijadikan responden. Seluruh karyawan akan diberikan daftar pertanyaan terkait hubungan komunikasi antar karyawan (aktor), lalu peneliti akan mencoba melakukan cross check, dimana hasil jawaban kuesioner dari responden awal sebagai informasi untuk menyebutkan data sampel selanjutnya sehingga jumlah sampel terpenuhi [14]. Atribut yang dilampirkan dalam kuesioner meliputi: departemen, umur, jenis kelamin dan jabatan. CV. Diamond Printing saat ini memiliki karyawan sejumlah 104 orang dari 7 departemen/divisi. Data kuesioner dari para responden ditabulasikan ke dalam Ms. Excel software dengan memberikan kode nilai "0" apabila tidak terdapat hubungan relasional dan kode 
nilai "1" apabila terdapat hubungan relasional kemudian datanya dipindahkan untuk diolah datanya menggunakan UCINET 6 software Versi 6.721 [15], [16]. Kuesioner terdiri dari dua bagian, yaitu name generator (menyebutkan aktor yg mmiliki hubungan komunikasi) dan name interpreter (konfirmasi terkait validasi data dari informasi aktor pertama) [2].

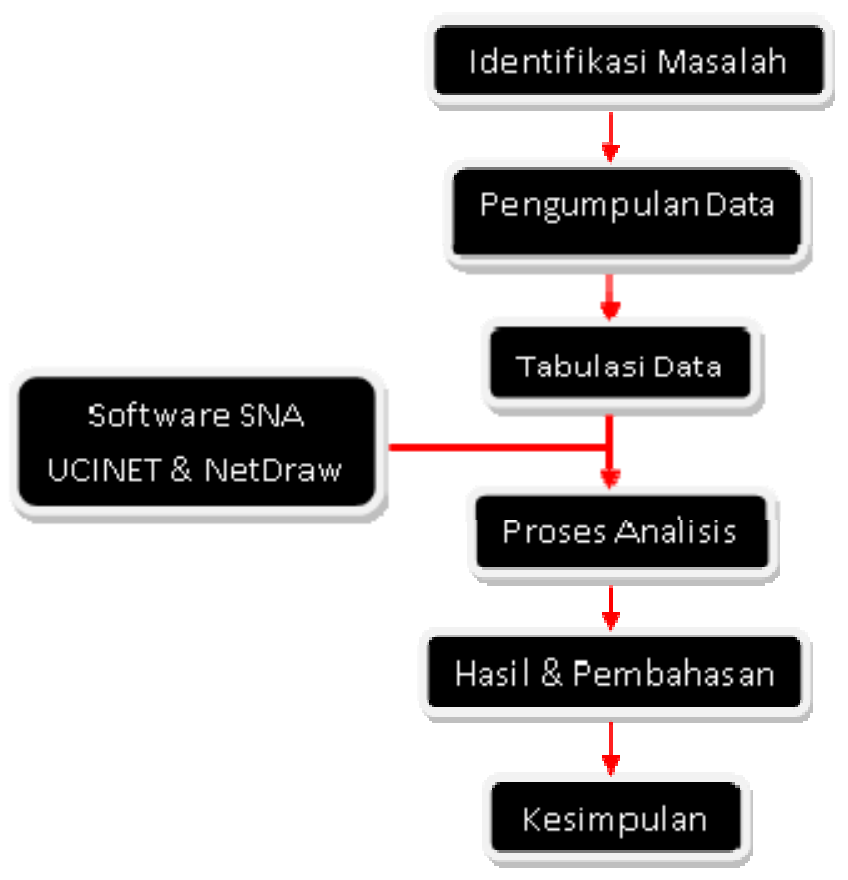

Gambar 1. Tahap Penelitian

\section{HASIL DAN PEMBAHASAN}

\subsection{Density}

Perhitungan density diolah dengan UCINET 6 software terlampir pada tabel 1 menunjukkan bahwa ada 371 ikatan yang terjadi dalam jaringan komunikasi. Nilai rata-rata density dalam jaringan komunikasi sebesar 3,7\% dan dapat ditarik kesimpulan hubungan antara individu lemah dimana nilainya kurang dari 50\%. Kepadatan jaringan (density) yang lemah bisa diselesaikan dengan berbagai terobosan yang dilakukan organisasi dengan lebih meningkatkan tingkat interaksi antar karyawan/pegawai, baik dalam satu departemen maupun inter departemen melalui berbagai acara yang bersifat formal sepeti rapat atau secara informal seperti sarasehan.

Tabel 1. Density

\begin{tabular}{lcc}
\hline \multicolumn{3}{l}{ Density/Average Matrix Value } \\
\hline 1. Density & 2. No. of ties & 3. Avg Degree \\
\hline 0,035 & 371 & 3,567 \\
\hline
\end{tabular}

\subsection{Degree Centrality}

Pada tabel 2 terlihat nilai dari degree centrality dalam struktur jaringan, tetapi yang memiliki tingkat kesukaan (populer) paling tinggi hanya beberapa orang saja dan peneliti hanya mencoba menampilkan 5 besar yang memiliki nilai tertinggi dari degree centrality. Dalam tabel 2 digambarkan individu nomor 46 merupakan karyawan perempuan dari departemen finishing dengan jabatan staff, memiliki tingkat kesukaan paling tinggi dengan nilai 7 (7 kali) 
menghubungi dan 1 (1 kali) untuk dihubungi. Hal ini memberikan tanda bahwa karyawan nomor 46 mengirimkan informasi kepada 7 karyawan lainnya di dalam struktur jaringan dan menerima informasi dari 10 karyawan lainnya dalam organisasinya. Nilai degree centraity atau tingkat kepuasan dapat menjadi bahan kajian oleh HRD atau bagian personalia CV. Diamond Printing dalam menempatkan karyawan-karyawan potensial untuk promosi jabatan, khususnya untuk level pengawas atau kepala bagian.

Tabel 2. Degree Centrality

\begin{tabular}{llccc}
\hline \multicolumn{5}{c}{ Freeman's Degree Centrality Measures } \\
\hline No. & OutDegree & InDegree & NrmOutDeg & NrmInDeg \\
\hline 46 & 7.000 & 1.000 & 6.796 & 0.971 \\
80 & 7.000 & 12.000 & 6.796 & 11.650 \\
74 & 7.000 & 5.000 & 6.796 & 4.854 \\
71 & 6.000 & 3.000 & 6.796 & 19.048 \\
37 & 6.000 & 6.000 & 5.825 & 2.913 \\
\hline
\end{tabular}

Sumber: data diolah, 2021

Sedangkan pada gambar 2 digambarkan karyawan yang memiliki tingkat kesukaan paling tinggi (degree centrality) terlihat di sociogram, dimana karyawan nomor 46 dan 37 (staf departemen finishing) 80 (HRD manager), 74 dan 71 (staf departemen lainnya/other) yang dilingkari warna merah merupakan lima orang dengan nilai degree centrality paling tinggi. Beberapa karyawan dari berbagai departemen menyatakan karyawan nomor 46 merupakan staf perempuan pada departemen finishing dengan masa kerja diatas 5 tahu, serta merupakan senior panutan oleh rekan-rekannya.

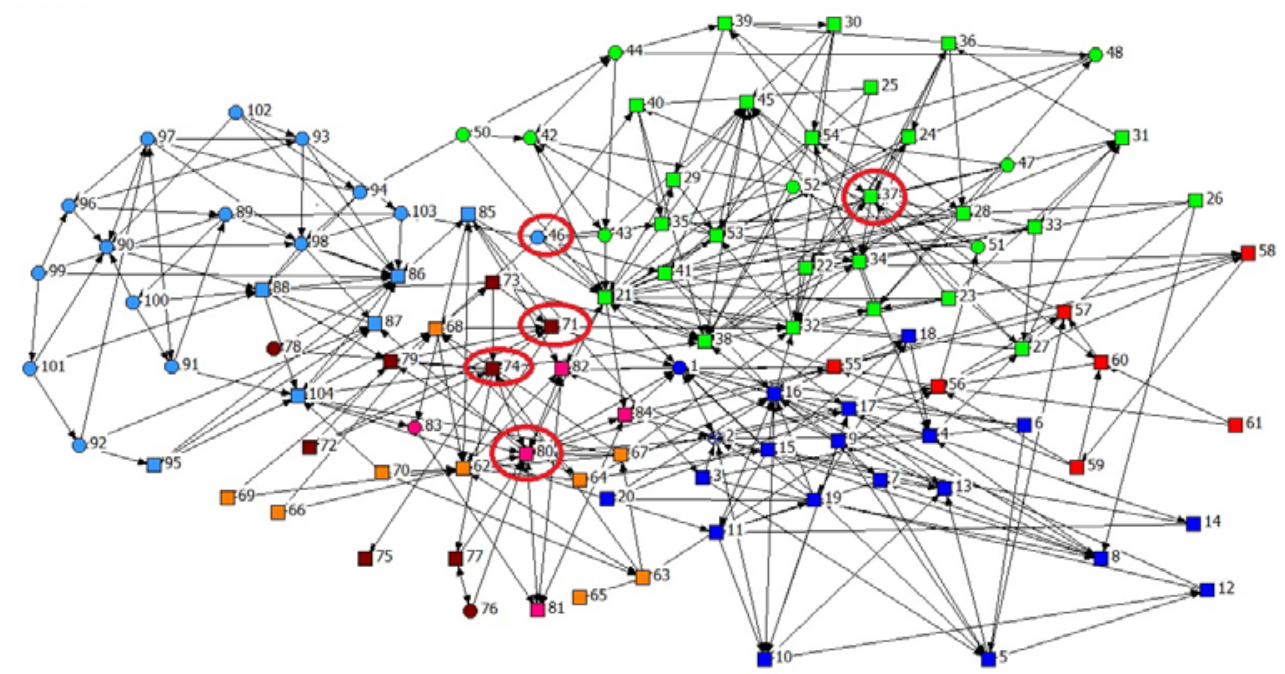

Gambar 2. Sociogram Degree Centrality

\subsection{Closenness Centrality}

Pada tabel 2 terlihat nilai dari closeness centrality dalam struktur jaringan, yang dapat dinilai berdasarkan dua parameter yaitu incloseness dan outcloseness. Dalam tabel 2 digambarkan bahwa closeness centrality tertinggi terdapat pada karyawan nomor 21 (finishing). Karyawan nomor 21 menjadi salah satu pegawai yang mempunyai kedekatan dengan depeartemen lain serta menjadi kolaborator. Kolaborasi antara beberapa karyawan hampir merata diantaranya ada karyawan nomor 80 (HRD manager), nomor 82 (direktur), nomor 78 (other) serta nomor 1 (cutting). 
Diharapkan kedepan CV. Diamond Printing dapat membuat berbagai inovasi agar tercipta berbagai kolaborasi yang baik antar departemen.

Tabel 3. Closeness Centrality

\begin{tabular}{rcc}
\hline \multicolumn{3}{c}{ Closeness Centrality } \\
\hline No. & inCloseness & outCloseness \\
\hline 21 & 16.119 & 5.687 \\
82 & 15.653 & 5.502 \\
80 & 15.630 & 5.774 \\
1 & 15.419 & 5.514 \\
78 & 15.305 & 0.962 \\
\hline
\end{tabular}

Sumber: data diolah, 2021

Sedangkan pada gambar 2 digambarkan karyawan yang memiliki tingkat kedekatan paling tinggi (closeness centrality) pada sociogram, dimana karyawan yang dilingkari warna merah karyawan nomor 21 (finishing), nomor 80 (HRD manager), nomor 82 (direktur), nomor 78 (other) serta nomor 1 (cutting). merupakan 5 besar nilai tertinggi closeness centrality. Berdasarkan informasi dari sebagian besar karyawan dari departemen finishing menginfokan karyawan nomor 21 merupakan karyawan laki-laki yang juga kepala bagian (KABAG) finishing dikenal ramah, supel, dan suka membantu rekan-rekannya.

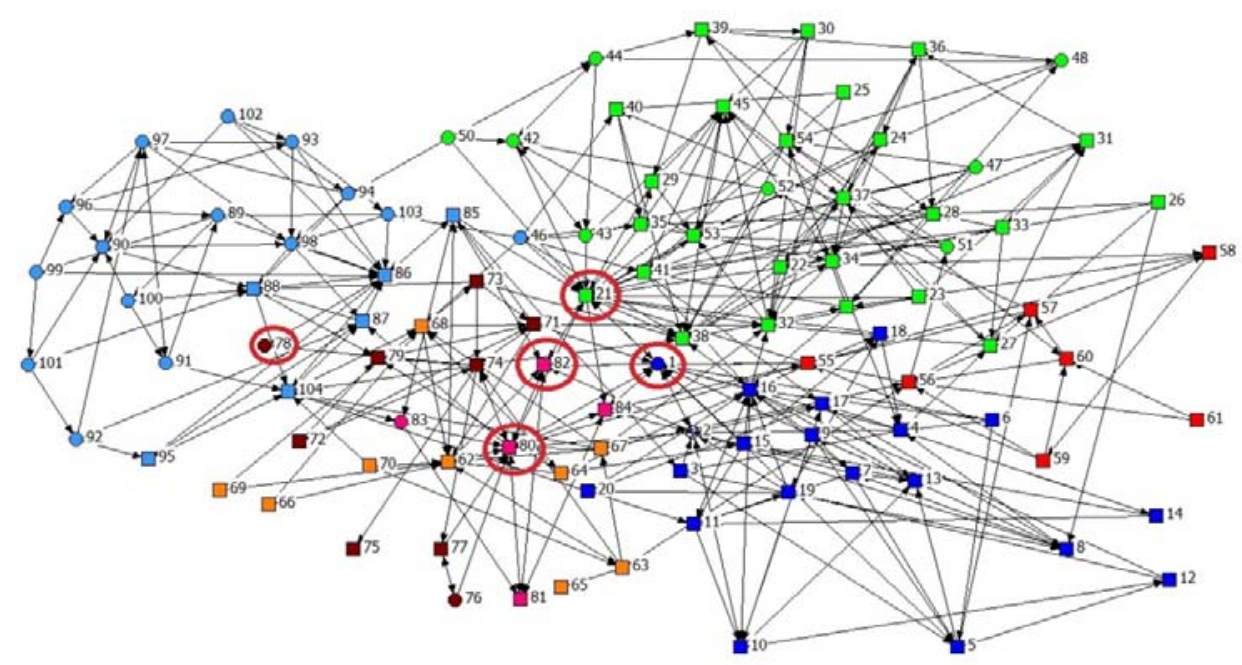

Gambar 3. Sociogram Closeness Centrality

\subsection{Betweenness Centrality}

Pada tabel 4 hasil perhitungan nilai betweenness centrality menggunakan UCINET 6 software diketahui karyawan yang memiliki nilai nBetweenness paling tinggi adalah karyawan laki-laki dengan nomor 21 (finishing) yang juga merupakan kepala bagian (KABAG). Karyawan nomor 21 merupakan favorit dalam struktur jaringan komunikasi dikarenakan banyak karyawan yang lain yang bergantung dalam jaringan pertemanan. Sedangkan posisi kedua hingga kelima ditempati oleh karyawan nomor 82 (direktur), nomor 80 (HRD manager), nomor 1 (printing) dan nomor 78 (other). Karyawan yang memiliki nilai betweenness centrality paling tinggi didominasi oleh karyawan dengan jabatan manajer da kepala bagian. Hal ini dapat terjadi karena beberapa 
karyawan yang memiliki jabatan manajer da kepala bagian dianggap orang yang paling mengerti dan memahami terkait seluk beluk pekerjaan dan permasalahan di perusahaan, sehingga diharapkan dengan ada berbagai terobosan dari perusahaan agar terjadi kolaborasi antar karyawan-karyawan di CV. Diamond Printing .

Tabel 4. Betweennness Centrality

\begin{tabular}{lcc}
\hline \multicolumn{3}{l}{ Freeman Betweenness Centrality } \\
\hline No. & Betweenness & nBetweenness \\
\hline 80 & 1884.012 & 17.933 \\
38 & 1367.726 & 13.019 \\
74 & 1360.265 & 12.948 \\
43 & 1324.501 & 12.946 \\
21 & 1259.990 & 12.607 \\
\hline
\end{tabular}

Sumber: data diolah, 2021

Sedangkan pada gambar 3 uıganuarkan кaryawan yang menjadi banyak pilihan dalam memberikan sebuah saran dan menyelesaikan setiap masalah pada rekan kerjanya serta memiliki nilai betweenness centrality paling tinggi pada sociogram, dimana karyawan yang dilingkari warna merah dengan nomor 80 (HRD manager), nomor 21, 38 dan 43 (finishing), dan nomor 74 (other) merupakan 5 karyawan teratas atau tertinggi nilai betweenness centrality nya. Berdasarkan informasi dari sebagian besar karyawan dari berbagai departemen menginfokan karyawan nomor 80 merupakan karyawan laki-laki yang juga manajer HRD dikenal ramah serta suka membantu seluruh karyawan yang memerlukan informasi terkait ketenagakerjaan.

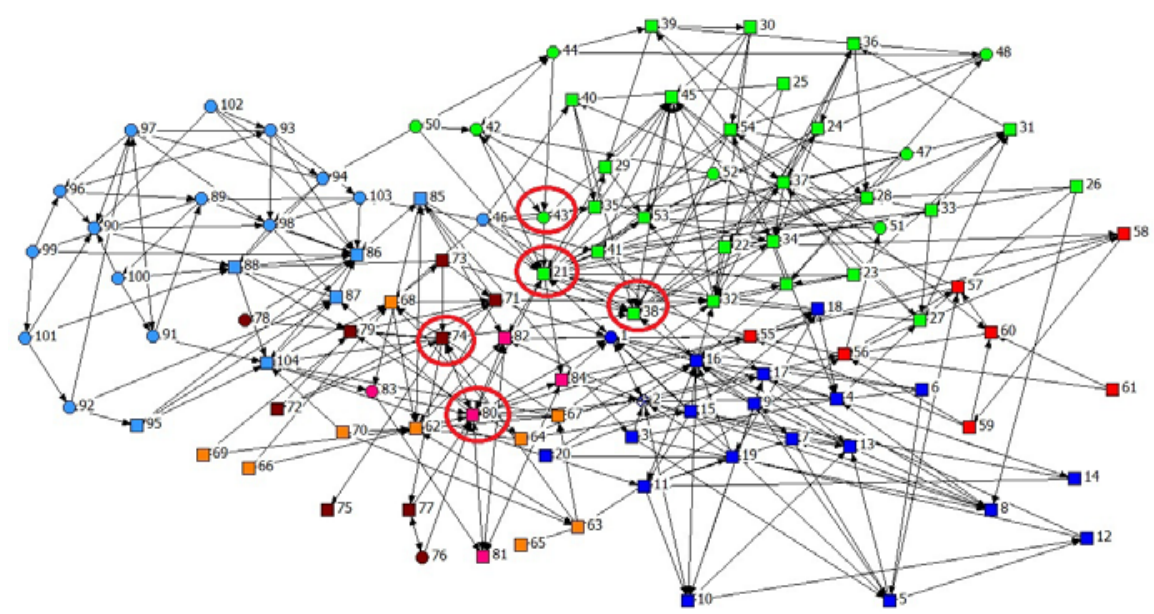

Gambar 4. Sociogram Betweenness Centrality

\subsection{Klik}

Berdasarkan hasil dari kuesioner yang diberikan pada responden didadaptkan hasil berupa adanya 2 klik yang dibatasi minimal 5 jumlah anggota yang dikelompokkan seperti pada tabel 5 yang menunjukkan bahwa klik hanya menampung 5aktor dari 104 aktor dalam struktur jaringan komunikasi. Berdasarkan pola klik yang ada banyak dominasi karyawan yang menjabat manajer dan kepala bagian (KABAG). Terdapatnya sebuah klok dalam perusahaan akan berdampak secara positif maupun negatif. Berdampak positif apabila klik tidak memiliki konflik kepentingan terkait antar karyawan serta meningkatkan kolaborasi yang efektif antar departemen. Sedangkan berdampak negatif apabila klik hanya dipandang sebagai sekumpulan karyawan yang membentuk 
faksi yang sifatnya destructive serta resistence terhadap perubahan perusahaan yang bersifat constructif.

Tabel 5. Klik

\begin{tabular}{cc}
\hline Klik & Karyawan \\
\hline I & $1,21,55,80,82$ \\
II & $1,21,55,80,84$ \\
\hline
\end{tabular}

Sumber : data diolah, 2021

\subsection{Sociogram}

Sebuah pola hubungan antara tiap karyawan (node) berdasarkan pada atribut departemen dan jenis kelamin yang dijabarkan dalam tabel 6, tabel 7, dan gambar 5. Beberapa departemen dibedakan berdasarkan warna pada node, dimana departemen printing warna biru tua, departemen finishing warna hijau, departemen cutting warna merah, departemen driver warna oranye, departemen lainnya (other) warna cokelat, departemen manager warna pink, dan departemen operational warna biru muda. Untuk membedakan jenis kelamin maka untuk simbol circle digunakan untuk karyawan wanita dan simbol square untuk karyawan berjenis kelamin laki-laki.

Tabel 6. Departemen atau Bagian

\begin{tabular}{lll}
\hline Departemen & Warna & \multicolumn{1}{c}{ Id Aktor } \\
\hline Printing & biru tua & $1,2,3,4,5,6,7,8,9,10,11,12,13$, \\
& & $14,15,16,17,18,19,20$ \\
Finishing & hijau & $21,22,23,24,25,26,27,28,29,30$, \\
& & $31,32,33,34,35,36,37,38,39,40$, \\
& & $41,42,43,44,45,46,47,48,49,50$, \\
& & $51,52,53,54$ \\
Cutting & merah & $55,56,57,58,59,60,61$ \\
Driver & oranye & $62,63,64,65,66,67,68,69,70$ \\
Other & cokelat & $71,72,73,74,75,76,77,78,79$ \\
Manager & pink & $80,81,82,83,84$ \\
Operational & biru muda & $85,86,87,88,89,90,91,92,93,94$, \\
& & $95,96,97,98,99,100,101,102,103$, \\
& & 104 \\
\hline
\end{tabular}

Sumber: data diolah 2021

Tabel 7. Jenis Kelamin

\begin{tabular}{ccc}
\hline No & Jenis Kelamin & Simbol \\
\hline 1 & Pria & Square \\
2 & Wanita & Circle \\
\hline
\end{tabular}

Sumber: data diolah 2021

Pada gambar 5 terlihat dalam sociogram bahwa sebagian besar didominasi oleh karyawan berjenis kelamin laki-laki sebanyak 77 orang $(74,04 \%)$ dibanding responden perempuan sebanyak 27 orang $(25,96 \%)$. Sociogram gambar 5 dapat dilihat kebanyakan melibatkan karyawan yang paling banyak melakukan kolaborasi dilakukan oleh karyawan level manajer dan kepala bagian 
(KABAG), diantaranya karyawan nomor 82 (direktur), nomor 80 (HRD manager), dan nomor 21 (KABAG finishing).

\section{KESIMPULAN}

Dengan menggunakan metode Social Network Analysis (SNA) dengan bantuan UCINET 6 software didapatkan hasil perhitungan density terdapat ada 371 ikatan serta nilai rata-ratanya lemah yaitu sebesar 3,7\% $(<50 \%)$ yang terjadi dalam jaringan komunikasi. Untuk karyawan yang memiliki degree centrality tertinggi adalah nomor 46 yang merupakan staf dari departemen finishing. Kemudian karyawan yang memiliki closeness centrality tertinggi adalah nomor 21 yang merupakan kepala bagian (KABAG) dari departemen finishing. Selanjutnya karyawan yang memiliki betweenness centrality tertinggi adalah nomor 80 yang merupakan manager HRD dari $\mathrm{CV}$. Diamond Printing. Sedangkan dalam pengelompokkan karyawan berdasarkan banyaknya tingkat interaksi atau klik dengan menggunakan batasan minimal 5 anggota kelompok didapatkan terdapat 2 klik. Dalam pola interaksi antar karyawan di CV. Diamond Printing masih didominasi serta berpusat pada karyawan dengan jabatan manajer dan kepala bagian (KABAG), sehingga diharapkan kedepan alur informasi dan pola interaksi bisa juga terjadi antar karyawan level staf.

Diharapkan kedepan manajemen dari CV. Diamond Printing lebih banyak mengadakan interaksi antar karyawan baik antar departemen maupun inter departemen agar terjadi sinergi sehingga pola komunikasi yang baik serta kolaborasi akan terjalin. Hendaknya karyawan dengan jabatan manajer dan kepala bagian (KABAG) bisa memberikan ilmunya, baik terkait dngan teknis pekerjaan maupun pengalaman bekerja sehingga terjadi transfer ilmu dan juga knowledge sharing.

\section{DAFTAR PUSTAKA}

[1] O. T. Jumrad and I. D. Mayang Sari, "Fungsi Komunikasi Dalam Organisasi Melalui Group Chat Whatsapp Oriflame," J. Common, vol. 3, no. 1, pp. 104-114, 2019.

[2] E. Zusrony, H. D. Purnomo, and S. Y. J. Prasetyo, "Analisis Pemetaan Jaringan Komunikasi Karyawan Menggunakan Social Network Analysis pada Perusahaan Multifinance," INTENSIF J. Ilm. Penelit. dan Penerapan Teknol. Sist. Inf., vol. 3, no. 2, p. 145, 2019.

[3] N. A. Siregar and Z. Ritonga, "The Analysis of Human Capital and Social Capital on Company Performance,” J. Online Jar. Pengaj. Seni Bina, vol. 14, pp. 139-143, 2019.

[4] A. P. Wardhani, H. Leonardo Budi, and M. Maria Magdalena, "Pengaruh Lingkungan Kerja, Komunikasi dan Kepemimpinan Terhadap Kinerja Pegawai," J. Manage., vol. 2, no. 1, pp. 344-354, 2016.

[5] A. Iriani and S. H. Priyanto, "Modeling Of Employee Relationships In Sme Batik: Case Study Of Windasari Batik," Asian J. Manag. Sci. Educ., vol. 2, no. 4, pp. 22-35, 2013.

[6] S. Yikwa, A. Nugroho, and M. N. N. Sitokdana, "Analisis Hubungan Sosial Anggota Himppar Salatiga Di Media Facebook Menggunakan Social Network Analysis," Pros. Semin. Nas. Inov. dan Apl. Teknol. di Ind., vol. 5, no. 2, pp. 70-79, 2019.

[7] D. Kurniawan, A. Iriani, and D. Manongga, "Pemanfaatan Social Network Analysis (SNA) Untuk Menganalisis Kolaborasi Karyawan pada PT. Arum Mandiri Group," J. Transform., vol. 17, no. 2, p. 149, 2020.

[8] C. Prell, "Becoming Familiar with Social Networks," in Social Network Analysis: History, Theory and Methodology, 2012, pp. 7-18.

[9] Eriyanto, Analisis Jaringan Komunikasi, Edisi 1. Jakarta: Kencana, 2014.

[10] M. T. Anwar, A. Iriani, and D. H. F. Manongga, "Analisis Pola Persebaran Pornografi pada Media Sosial dengan Social Network Analysis," Buana Inform., vol. 9, no. 1, pp. 43-52, 2018.

[11] S. P. Borgatti, M. G. Everett, and J. C. Johnson, "10 Centrality BT - Analyzing Social Networks," in Analyzing Social Networks, 2013, p. 304.

[12] S. P. Borgatti, M. G. Everett, and J. C. Johnson, Analyzing Social Networks, 2nd Editio. 
London: SAGE Publication Ltd, 2018.

[13] F. N. Maulidya, W. Witanti, and A. I. Hadiana, "Pembangunan Sistem Informasi Pola Hubungan Kerja Antar Tenaga Medis Pada Rumah Sakit Jiwa Provinsi XYZ Menggunakan Social Network Analysis," in Prosiding Seminar Nasional Sains dan Teknologi ke-9, 2018, pp. 214-219.

[14] I. Etikan, "Comparision of Snowball Sampling and Sequential Sampling Technique," Biometrics Biostat. Int. J., vol. 3, no. 1, 2017.

[15] Y. Wu and Z. Duan, "Social network analysis of international scientific collaboration on psychiatry research," Int. J. Ment. Health Syst., vol. 9, no. 1, 2015.

[16] A. Syarifudin et al., "Pemetaan Rekanan Pada Jaringan Sistem Pengadaan Secara Elektronik (SPSE) dengan Social Network Analysis (SNA)," in Seminar Nasional Informatika 2018, 2018, pp. 43-50. 